\title{
Erratum to: Use of three-dimensional computed tomography overlay for real-time cryoballoon ablation in atrial fibrillation reduces radiation dose and contrast dye
}

\author{
B. Oude Velthuis ${ }^{1}$ M. M. D. Molenaar ${ }^{1}$ H. G. Reinhart Dorman ${ }^{2}$ J. Y. Stevenhagen ${ }^{1}$ M. F. Scholten ${ }^{1}$ \\ J. van der Palen ${ }^{3,4} \cdot$ J. M. van Opstal ${ }^{1}$
}

Published online: 19 June 2017

(C) The Author(s) 2017. This article is an open access publication.

\section{Erratum to:}

Neth Heart J (2017)

DOI: 10.1007/s12471-017-0962-7

In the version of the article originally published online the name of the second author was incomplete and should have read: M.M.D. Molenaar

Open Access This article is distributed under the terms of the Creative Commons Attribution 4.0 International License (http:// creativecommons.org/licenses/by/4.0/), which permits unrestricted use, distribution, and reproduction in any medium, provided you give appropriate credit to the original author(s) and the source, provide a link to the Creative Commons license, and indicate if changes were made.

The online version of the original article can be found under doi: 10.1007/s12471-017-0962-7

B. Oude Velthuis

b.oudevelthuis@mst.nl

1 Thorax Centre Twente, Medisch Spectrum Twente, Enschede, The Netherlands

2 Department of Cardiology, Bravis Ziekenhuis, Roosendaal, The Netherlands

3 Department of Research methodology, Methods and Data Analysis, University of Twente, Enschede, The Netherlands

4 Medical School Twente, Medisch Spectrum Twente, Enschede, The Netherlands 


\section{Advertisement placed here.}

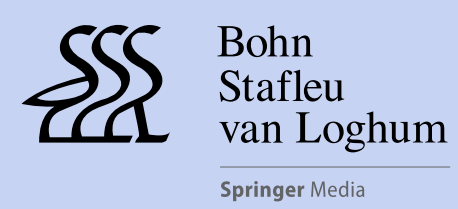

Houten 2017 